\title{
Alteração do Processo de medicação como apoio na redução do tempo Médico-Alta no Pronto Atendimento
}

\begin{abstract}
Resumo:
Introdução: Os pacientes manifestam constantemente sua insatisfação com o tempo em que permanecem no setor de Pronto Atendimento para diagnóstico, Medicação,definiçao de conduta e desfecho, de 72 queixas em Novembro, $47 \%$ foi relacionado ao tempo de permanência.O principal objetivo foi verificar e atuar em pontos de restrição entre o atendimento Médico e a alta.A demora também retarda a entrada de outros pacientes, aumenta os riscos assistenciais e drena recursos para cuidar de pacientes que não deveriam mais estar no setor, diminuindo a efetividade operacional,após utilização da ferramenta de qualidade Diagrama de Pareto, identificamos uma oportunidade de melhoria para redução do tempo para o processo de medicação;Métodos: Testar o método do processo de medicação dividindo às etapas, entre preparo e administração por profissionais no Pronto Atendimento Adulto de um hospital privado, utilizando a teoria da Ciência da Melhoria e ciclo de PDSA (Plan-planeje, Do -fazer, Study -analise, Act-aja) para verificar e corrigir os pontos de restrições. Resultados: Após 20 semanas de PDSA, o tempo do atendimento da solicitação via prescrição, reduziu de $16 \mathrm{~min}$. com variação irregular para 12 minutos com variação regular, redução do tempo Médico-alta de $130 \mathrm{~min}$. com variação irregular para $113 \mathrm{~min}$. com variação regular, após o tempo de PDSA foi realizado pesquisa de forma anônima com os colaboradores e $85,5 \%$ responderam que o processo é melhor para sua atuação e $89,9 \%$ que é melhor para o paciente.
\end{abstract}

Autor: Getúlio Gregorio da Silva

Co-autores: Julio César de Lima,Denise de Almeida Costa,Gislaine Saraiva Magalhães,Tatiane Galhardi Saraiva 